\title{
Hay primeros estudios que indican que se ha trasladado el grueso de la interpretación a la remota
}

\section{Early studies indicate that the bulk of interpreting has shifted to remote}

\section{Óscar Jiménez SERRANo}

Departamento de Traducción e Interpretación, Universidad de Granada ojimene@ugr.es

\section{INTRODUCCIÓN}

Oscar Jiménez habla sobre la situación actual de la interpretación profesional de conferencias y de la disrupción que supone la aplicación masiva de las nuevas tecnologías de la información y comunicación. En esta entrevista, llena de interesantes anécdotas, analiza el espacio que ha venido a ocupar la modalidad de la interpretación simultánea remota. También realiza una valoración de las implicaciones que tienen las nuevas tecnologías en la docencia de la interpretación simultánea.

Palabras clave: interpretación simultánea remota; tecnologías aplicadas a la interpretación. 


\section{ENTREVISTA}

Fecha: 12/2/2020

Martín Azcárate: Hoy tenemos un invitado de categoría. Nos acompaña Óscar Jiménez Serrano, traductor e intérprete profesional con más de 30 años de experiencia. Además, es profesor titular del Departamento de Traducción e Interpretación de la Universidad de Granada. En los últimos años su actividad se ha centrado en la relación que existe entre la interpretación y las nuevas tecnologías, algo que es muy interesante hoy en día. Además, ha sido invitado a impartir talleres y seminarios en muchas instituciones, ha interpretado en la ONU, en la Unión Europea, en los premios Príncipe de Asturias y un largo etcétera.

Manuel de la Cruz: Buenas tardes, Óscar Jiménez. ¿Qué tal? ¿Cómo va todo por Granada? ¿Estáis sobreviviendo al tsunami?

Óscar Jiménez Serrano: Buenas tardes, Manuel. Encantadísimo de estar con vosotros. Soy un fan de la Universidad de Salamanca desde hace mucho tiempo y estoy encantado de estar hoy con vosotros en el programa. En Granada estamos regular, la verdad. Somos un punto bastante negro del mapa del covid, como sabéis. Estamos bastante encerrados, tenemos toque de queda a las 10, tiendas cerradas, bares cerrados... Pero bueno, vamos sobreviviendo.

MDLC: A colación de lo que me estás diciendo, hemos seguido las noticias de la Universidad de Granada e igual, igual que todos, también habéis tenido que dar el salto al online. Nos ha apabullado esta digitalización de repente. En estos últimos 7 meses, ¿cómo lo habéis vivido vosotros allí?

OJS: Pues ha sido difícil, como imagino que en muchas otras muchas universidades del país. Nos sorprendió el año pasado en marzo la pandemia, como a todos, y reaccionamos como pudimos. Virtualmente, evidentemente, con docencia online. Este año lo hemos arrancado presencialmente, o mejor dicho en la modalidad que llaman ahora "híbrida», en la que dividíamos los grupos y la mitad de la clase estaba a distancia y la otra mitad, presencial. Pero debido a las cifras a las que llegamos, sobre todo en octubre, hubo que volver a lo virtual. Actualmente estamos en esa situación.

MDLC: ¿Y estáis utilizando algún tipo de plataforma determinada, algo que os esté ayudando a poder trabajar, por ejemplo, en la simultánea? Porque uno de los problemas a los que nos vemos abocados ahora mismo es que no tenemos, a lo mejor, la plataforma ideal para poder enseñar la interpretación simultánea. Después, también, los escasos conocimientos que tenemos en remota.

OJS: Claro. Bueno, no sé si sabéis que Granada es un poco peculiar en cuanto a la estructura del grado y no tenemos en absoluto simultánea en el grado. En el grado

Óscar JIMÉNEZ SERRANO

Hay primeros estudios que indican que se ha trasladado el grueso de la interpretación a la remota
CLINA

vol. 7-1, June 2021, 43-55

elSSN: 2444-1961

Ediciones Universidad de Salamanca - CC BY-NC-ND 
damos bilateral, consecutiva y traducción a vista, pero la simultánea se deja para nuestro máster. Sabéis que es uno de los pocos másteres públicos en interpretación de conferencias y es ahí donde se hace simultánea. El año pasado, cuando nos pilló la pandemia, efectivamente, quedaban bastantes clases por dar de simultánea en el máster. Hicimos lo que pudimos en esa situación. Este año todavía no hemos empezado con simultánea, empezaremos en breve, y estamos barajando la posibilidad de conseguir plataformas específicas, estamos justo ahora en ello. Hay maneras de resolver la enseñanza de simultánea virtualmente y no en el laboratorio, que es lo habitual, pero, evidentemente, no es lo mismo. De todos modos, quiero señalar que la Universidad de Granada nos ha dado una especie de venia en lo que considera las enseñanzas de interpretación simultánea, sobre todo, y consecutiva como prácticas. Al ser prácticas, nos permiten, en una situación en la que la mayoría de las enseñanzas son virtuales, que sean presenciales porque tenemos grupos reducidos: el aislamiento de la cabina, que ayuda mucho. Cada estudiante puede estar en una cabina y eso hace que no entre en contacto con otros estudiantes. Y esperamos que sea también una solución. Si conseguimos que las cifras vuelvan a una cosa normal, que sea transitable, yo creo que volveremos a la presencial.

MDLC: Martín, tú hace un momento estabas comentándome qué va a pasar con vosotros, con la educación, qué os vamos a dar en interpretación, por ejemplo, simultánea.

MA: Yo me estaba preguntando cómo afecta esto a los estudiantes, digamos, de aquí a dentro de unos años. Si los estudiantes vamos a tener que, para formarnos en interpretación, dominar las nuevas tecnologías y todas las opciones que nos ofrecen, porque a partir de ahora se va a empezar a aprovechar muchísimo más para la interpretación.

OJS: Efectivamente, muy buena pregunta, Martín. Yo creo que, de entrada, va a ser seguro una ventaja comparativa con respecto a tu competencia, es decir, cada estudiante o futuro intérprete que se forme en ese aspecto va a tener una ventaja comparativa, porque está cambiando todo por las nuevas tecnologías. Si será obligatorio absolutamente o no dependerá también de la evolución de la pandemia. Ahora mismo dependemos de las vacunas, dependemos de cómo serán esas nuevas realidades, pero a fecha de hoy ya os está afectando. Yo he comentado mucho esto con mis estudiantes últimamente. Van a ser la primera promoción que van a salir al mercado cuando no hay prácticamente interpretación presencial. Ahora, no nos engañemos, hay muy poca, por no decir poquísima. Sin embargo, se está haciendo muchísimo más remota. Hay primeros estudios que indican que se ha trasladado el grueso de la interpretación a la remota. Entonces, a fecha de hoy, ya es algo que debéis tener en cuenta, por supuesto.

Óscar JimÉnEz SERRANO

Hay primeros estudios que indican que se ha trasladado el grueso de la interpretación a la remota
CLINA

vol. 7-1, June 2021, 43-55

elSSN: 2444-1961

Ediciones Universidad de Salamanca - CC BY-NC-ND 
MDLC: Rosa, tenías una pregunta, ¿no?

Rosa Weber: Sí, Óscar, mencionaste hace unos segundos que utilizáis, o que vais a utilizar, plataformas en el máster para la interpretación remota. ¿Nos podrías explicar un poco en qué consisten, cómo ayudan y cómo funcionan?

OJS: Sí, claro. Fundamentalmente, son plataformas que lo que crean es una especie de cabina virtual. Por ejemplo, supongo que estáis al tanto de que se está interpretando ahora mucho con Zoom, el programa que estamos utilizando para esta videoconferencia. Pero Zoom no es una plataforma de interpretación. Zoom ha aprovechado que el Pisuerga pasa por Valladolid y ha puesto una nueva funcionalidad para que se pueda hacer interpretación, pero no es una plataforma de interpretación. Sin embargo, sí había ya plataformas anteriormente de interpretación remota, con las que yo había trabajado antes de la pandemia, que ahora se están reconvirtiendo para ofrecerse para la docencia. Por ejemplo, conozco una en concreto, con la que yo había trabajado, que se ha ofrecido ya específicamente como una especie de cabina virtual para poder trabajar por ahí la simultánea. En eso consiste, básicamente. Tú tienes una especie de consola virtual que se parece mucho más a una cabina y que tiene funcionalidades de la cabina, porque en Zoom, por ejemplo, no tienen los cambios de turnos, son muy complicados, hacer una pausa es muy complicado... Todo esto sí lo tienen estas cabinas. Y luego la posibilidad de grabar las interpretaciones, etc.

MP: Me gustaría preguntarle si la interpretación simultánea remota ya venía pisando fuerte, debido tanto a la evolución de la tecnología como del mercado... entiendo que la pandemia ha acelerado esta etapa de transformación de la profesión sin una posibilidad, quizás, de retorno. En su artículo «Foto fija de la interpretación simultánea remota al inicio de 2020» para la revista Tradumática, trata las diferentes medidas idóneas para la realización del ejercicio. Creo que, obviamente, no se habrán podido implementar con el tiempo suficiente. ¿Cree que esto hará que la profesión se resienta al provocar que quede a medio camino entre la presencial y la remota?

OJS: Evidentemente, esa revolución ya había comenzado, y yo la anunciaba justo tres meses antes de la pandemia. Parece que fue premonitorio el artículo. De hecho, es increíble la acogida que está teniendo. Me llamó la directora de la revista diciendo «tiene una segunda vida el artículo desde marzo", podéis ver las cifras de estadísticas de lectura que, en nuestro campo modesto del intérprete - no el público en general, pero para nuestro campo modesto - son muy altas. Por eso parecía que era premonitorio. Y ha habido una absoluta explosión. Yo he leído ya cifras de aumentos de hasta triplicarse incluso la interpretación remota que se hacía desde antes de la pandemia a después de la pandemia... Pero yo creo que incluso más del triple. Y evidentemente lo va a cambiar y lo está cambiando todo. De hecho, como decía antes, prácticamente

Óscar JIMÉNEZ SERRANO

Hay primeros estudios que indican que se ha trasladado el grueso de la interpretación a la remota
CLINA

vol. 7-1, June 2021, 43-55

eISSN: 2444-1961

Ediciones Universidad de Salamanca - CC BY-NC-ND 
ya no hacemos interpretación presencial en estas fechas y casi todo es o bien remoto o, algo que me parece muy interesante, que es lo que se ha venido llamando «híbrido", es decir, que hay una parte física y otra parte que no lo es. Por ejemplo, yo ya he tenido ocasión de hacer esto en varias ocasiones. En Málaga en septiembre se realizó un congreso muy interesante en el que nosotros estábamos físicamente allí en el hall del Palacio de Congresos, de manera abierta, para que no hubiera problemas de contagio y demás; y luego el 80 o 90\% de los asistentes al congreso eran virtuales y nos veían por internet. Entonces, nuestra interpretación saltaba a las ondas. Luego se hacía toda la recreación como si fuese un programa de televisión en el que se planificaba a qué sala vamos, con qué intérprete contactamos... Y fue muy interesante todo. Estos entornos híbridos también hay que tenerlos en cuenta.

JDLP: En los últimos meses he contactado con y leído sobre algunos intérpretes profesionales cuya pasión es la interpretación y trabajan de ello. Sin embargo, he visto que una gran mayoría de ellos no se dedican exclusivamente al ejercicio de interpretación, sino que a lo mejor también traducen, son docentes en la Universidad, escriben... Mi pregunta es: ¿en los estándares de la industria en 2020, tal y como funciona la interpretación, sería posible mantener un nivel de vida estable y unos ingresos estables trabajando exclusivamente como intérprete?

OJS: Bien. La respuesta: posible es, por supuesto. Conozco muchos casos en que es así. Sin embargo, es cierto que para la mayoría de los intérpretes no es la única actividad que ejercen, por razones obvias. En primer lugar, la interpretación es un trabajo muy estacional. Estoy hablando de la época prepandemia, ahora ya está todo absolutamente desquiciado y no se sabe cuándo empieza una temporada alta o cuando no, pero sí hay temporadas altas. Por ejemplo, en el mercado español claramente de septiembre a noviembre hay mucho más trabajo, de marzo a junio hay mucho más trabajo; y hay épocas como Navidad o verano en las que prácticamente no hay trabajo. Claro, un intérprete que tiene todo el verano libre, que hace muy poco o nada de interpretación, o en la época de noviembre, diciembre, enero, evidentemente, traduce. Luego hay muchísimos, como dices, profesores universitarios que se dedican a otras actividades. Por tanto, es perfectamente posible. Hay muchos casos en que es así, pero es una actividad que se presta mucho a compatibilizarla con otras y a nadie le viene mal un ingreso adicional. De todos modos, lo que sí tengo que decir es que todos mis compañeros intérpretes que además traducían y desempeñaban otras actividades están dando gracias a Dios ahora por ello, porque en esta época ha bajado muchísimo el nivel de trabajo en interpretación y, si no, estarían prácticamente ociosos. Porque o se consigue algún encargo en remota o poca cosa. Claro, la interpretación presencial prácticamente ha desaparecido, por desgracia.

Óscar JimÉnEz SERRANO

Hay primeros estudios que indican que se ha trasladado el grueso de la interpretación a la remota
CLINA

vol. 7-1, June 2021, 43-55

elSSN: 2444-1961

Ediciones Universidad de Salamanca - CC BY-NC-ND 
MDLC: Recogiendo un poco las ideas que han apuntado ya Rosa, Miguel y Juan, este nuevo intérprete, esta nueva profesión que se está configurando ahora mismo, que todavía no sabemos dónde va a llegar porque estamos en un momento bastante incipiente, aunque no tan incipiente, porque como tú ya ves, ya vosotros ya habéis trabajado en los noventa con otro tipo de sistemas de interpretación a distancia. Pero, ¿crees que hoy en día tal y como están las cosas el intérprete se está convirtiendo en una especie de «persona orquesta»? Además, estas nuevas tecnologías están afectando también al tema de la reducción de costes y eso afecta, o también podría afectar, incluso, a la calidad.

OJS: Por supuesto. Me parece una pregunta magnífica, Manuel. Porque, en efecto, desde hace mucho tiempo existía la remota, no como la conocemos ahora, sino el hecho de no estar o el intérprete o los asistentes físicamente en el mismo sitio. Por videoconferencia llevamos muchos años interpretando. Yo llevo 16 años haciendo los Premios Príncipe, primero, y luego Princesa de Asturias, debajo del Teatro Campoamor, viendo por vídeo lo que está sucediendo sin estar físicamente en el lugar donde se está produciendo el acto. Pero ahora ha cambiado todo, en el sentido de que hay muchísimas más situaciones posibles y perfectamente, como tú dices, hay que ser una «persona orquesta». Sin ir más lejos, anoche mismo estuve interpretando un partido de la UEFA del Granada, que es el equipo local, en el que se hacía por Zoom la rueda de prensa. Yo estaba físicamente en la sala de prensa del Granada y, de pronto, falló el Zoom. Empezó a haber reverberación y yo no entendía la pregunta, y tuve yo que proponer que si me trasladaba físicamente a la zona del atril, al lado de los oradores, para escucharles directamente; iy funcionó! Yo pude hacerlo directamente; salía bien porque no entraba el eco por fuera y eso, si no está el intérprete para asesorar y decir "pues creo que si probamos esto funcionaría mejor», probablemente habría sido un desastre. Porque se producen esos problemas técnicos que son inevitables, todos los días los vivimos. Ahora mismo podríamos empezar a tener problemas técnicos en esta reunión de Zoom. Y eso es lo que crea muchísima incertidumbre. Yo creo que uno de los principales problemas de todo esto para el intérprete es el aumento tremendo del estrés. Fijaos que incluso se ha llegado a reducir a la mitad el tiempo de turnos en cabina en interpretación simultánea. Ahora ya no cambiamos cada 30, cambiamos cada 15 o 20 en remota porque el estrés es mucho mayor y acabas mucho más agotado. Por ejemplo, las jornadas de 7 horas típicas de interpretación son casi impensables en virtual.

MDLC: Por ejemplo, trabajar en pareja, trabajar con un compañero. Las exigencias van a depender mucho también de la localización, si estáis los dos deslocalizados, si vais a estar en el mismo sitio... ¿Cómo se están solucionando estos problemas técnicos? ¿Se puede trabajar en equipo todavía o la cosa es difícil? Por ejemplo, trabajar con un compañero con Zoom.

Óscar JIMÉNEZ SERRANO

Hay primeros estudios que indican que se ha trasladado el grueso de la interpretación a la remota
CLINA

vol. 7-1, June 2021, 43-55 elSSN: 2444-1961

Ediciones Universidad de Salamanca - CC BY-NC-ND 
OJS: Yo creo que has dado en el clavo, porque el otro gran factor, junto con el estrés generado por la incertidumbre del fallo tecnológico, de las deficiencias tecnológicas, es el hecho del trabajo en pareja, con el compañero, en equipo. Se convierte en algo mucho más difícil y que, a veces, incluso, es casi imposible. Se están empezando a desarrollar opciones. Por ejemplo, esta empresa que yo dije que ofrece este tipo de sistemas modificó, a través de sus distintas versiones, la posibilidad de interactuar; pero, por ejemplo, se sigue utilizando el chat. A mí no me parece el chat en absoluto una manera de poder comunicarte con tu compañero. Yo, cuando estoy interpretando en simultánea, no puedo concentrarme en escribir en el chat. Bastante difícil es la simultánea, que es una actividad absolutamente antinatural, como sabemos. Que preparamos nosotros a los estudiantes, pero el hombre no ha nacido para hacer simultánea. Hemos conseguido hacerlo, pero no venimos de fábrica preparados para eso. Bastante difícil es como para tener que estar con un chat diciendo «oye búscame el término tal» o "qué tal me oyes». Es muy complicado. Ahora, se pueden ir haciendo parches. Por ejemplo, yo suelo hablar con mis compañeros antes, sobre todo, si los conozco, los llamo antes. "Oye, ¿cómo vamos a hacer el cambio de turnos? ¿Qué te pongo? ¿Te pongo ‘voy' o 'entro en un minuto' o ‘ya'?’. Pero, inevitablemente yo creo que, por el retardo del sistema y el hecho de que el cambio es más difícil, siempre va a haber incidencias. Es decir, se va a terminar de oír la frase del intérprete que cambia y luego el otro, a lo mejor, se va a perder el principio. Creo que todo esto ha salido muy perjudicado, pero esa angustia de no tener a alguien que, visualmente, tú estás con un compañero en cabina y con los ojos ya le dices «búscame ese término»... Eso es imposible hacerlo habitualmente porque, además, no se te ve. Estás, obviamente, aislado. Es probablemente lo que más se resiente, Manuel.

MDLC: En cuanto a la percepción que tenemos hoy en día de la remota con respecto a la que teníamos, no me voy a ir muy lejos, con la que tenemos respecto hace 8 meses o cuando sale publicado tu artículo en enero del 2020, ¿ha cambiado entre los profesionales y las asociaciones de profesionales? ¿Hemos tenido que acelerar todo el proceso de repente? ¿Cuál es tu percepción? ¿Qué es lo que está pasando entre las asociaciones, entre los compañeros? ¿Cómo lo percibes? ¿Cómo se percibe?

OJS: Pues fantástica pregunta también, porque a mí es de lo que más me ha preocupado. Yo he intentado hacer proselitismo desde el 17 que empecé a hablar de este tema en un curso que me invitaron en AICE, la Asociación de Intérpretes de España, en la sede en Madrid, diciendo que tenemos que empezar a afrontar este tema y hablar de él. AICE ha publicado unas directrices públicas y yo las recojo en mí artículo. Las publicó en el 19 y las ha actualizado, icuriosamente!, en marzo del 2020, justo con la pandemia, y las ha vuelto a actualizar en mayo del 2020, creando incluso una guía de referencia para la interpretación remota. Hay unos intentos de las asociaciones. AICE, está publicado también en el artículo, recoge una serie de temas, de ventajas,

Óscar JIMÉNEZ SERRANO

Hay primeros estudios que indican que se ha trasladado el grueso de la interpretación a la remota
CLINA

vol. 7-1, June 2021, 43-55

elSSN: 2444-1961

Ediciones Universidad de Salamanca - CC BY-NC-ND 
desventajas, recomendaciones... El problema es si esas recomendaciones luego se llevan a la práctica. Yo he trabajado mucho y también he publicado cosas sobre interpretación en la televisión. Es un tema que me gusta y que he tenido oportunidad de trabajar por mi profesión y hay unas recomendaciones de AICE sobre cómo tiene que ser la interpretación en la televisión, pero luego no se producen realmente. Yo cuando voy a la televisión y trabajo allí no me ofrecen esas condiciones. Entonces, lo que hay que hacer es intentar ser realista y, por ejemplo, si queremos normalizar el inglés técnico, pues hay que ser realista porque el inglés entra de todos modos. Pues eso, hay que ver cómo es la situación e intentar conseguir unos mínimos innegociables en el trabajo que se puedan desarrollar. Pero luego, muy importante también, los compañeros. ¿Qué opinan los compañeros? Yo he generado y he creado reuniones aquí, en Granada, y en Andalucía, para hablar de este tema. Nos hemos ido a tomar café y «oye, ¿qué hacemos? ¿Cómo vamos a reaccionar a la remota?». Es muy complicado. Lo que siempre veía era lo que se dice en inglés «wait and see». Esto va a cambiar todo, pero todavía no del todo. Yo todavía tengo congresos presenciales, vamos a ir viendo. Ahora ya no se puede decir «vamos a esperar». Ha explotado en la cara. Yo ya cerraba el artículo, fijate que todavía no estaba la pandemia, diciendo «es momento ya de hablar. Tenemos que sentarnos a ver qué va a pasar con esto". Ahora ya no hay más remedio, la pandemia ha explotado, todo ha cambiado, la remota está por todas partes y ahora todo el mundo dice "sí, ahora hay que hacerlo». Pero hay que hacerlo ya. Ha habido reuniones enormes, y con esto termino, que sé que me estoy alargando un poco. Estuve en una reunión virtual con casi 200 intérpretes de todo el mundo, justo en plena pandemia, fue en marzo o abril, y todo el mundo estaba muy interesado en ello, pero no termino de ver yo posturas claras. Se apuntan las desventajas, que hay que arreglarlas, pero la interpretación remota se sigue produciendo y los problemas se siguen produciendo.

RW: Hablando de los problemas, yo me he preguntado, ¿qué hacéis cuando pasa justo esto? Cuando la imagen se congela, cuando el audio no te llega... Porque ahora tenemos mucha suerte, parece que todos tenemos una conexión bastante buena y nos escuchamos bien. Pero, ¿hay un back-up plan o algo que puedas hacer cuando se congela o se va?

OJS: Depende de la situación, Rosa, pero pocas cosas puedes hacer en ciertas circunstancias. Y lo pasas muy mal. Te sube enormemente la adrenalina, el estrés y las pulsaciones, intentas arreglarlo, como este caso que yo contaba ayer, que conseguimos solventarlo, pero hay otras veces que sí falla la conexión. A mí me ha pasado, por ejemplo, por poner un caso, estar interpretando en remota y perder la conexión, tener que mandar un WhatsApp a la compañera: «entra tú». Pero, claro, se desequilibra ya todo, porque sabes que nos repartimos turnos. Entonces yo en ese caso, para compensarla, le hice luego un turno más largo, luego le falló a ella y me volvió a mí la

ÓsCar JIMÉNEZ SERRANO

Hay primeros estudios que indican que se ha trasladado el grueso de la interpretación a la remota
CLINA

vol. 7-1, June 2021, 43-55

elSSN: 2444-1961

Ediciones Universidad de Salamanca - CC BY-NC-ND 
interpretación, y acabé haciendo casi una hora seguida yo solo. Eso es una barbaridad cuando estás en remota. Entonces, ¿todo esto cómo puedes prevenirlo? Pues hay que resolverlo y ya está. El problema principal, a mí me parece, es que el intérprete se «autotraslada» ese estrés, lo que no debería suceder, porque en el mercado presencial, cuando todo era presencial, si se caía el equipo en cabina el intérprete decía «o sentimos, no funciona el equipo»; y tú te quedabas esperando que el técnico lo arreglara. Pero ahora es como si fueras parte de ello porque tú estás conectado, no te están oyendo y no puedes evitar sentirte partícipe, aunque tú no tengas nada que ver con el problema técnico. Y esto es lo que más me preocupa, porque no hay manera de quitarse esa sensación de que tú eres parte y que tú lo pasas mal. No te quedas relajado «bueno, se ha caído la red y yo espero que vuelva». No, tú estás mucho más agobiado. A mí me ha pasado muchas veces de caerse el equipo de simultánea y tener que bajar a la sala a hacer consecutiva. Pues bajas, haces consecutiva y ya está. Pero ahí ¿qué vas a hacer, si la reunión es a lo mejor en Buenos Aires? No vas a ir a Buenos Aires a hacer la consecutiva.

RW: Sí y, aparte de la sensación misma que tú tienes si te falla la conexión, ¿los que te dan el encargo también te perjudican o lo entienden?

OJS: Claro. Una pregunta muy interesante también. De hecho, si os fijáis, en el artículo hice una encuesta a 4 agentes distintos y entre ellos estaban los técnicos, estaba la organizadora del congreso, las asociaciones, etc. Es que todos están implicados. Normalmente los que organizan el congreso lo pasan igual de mal que tú, intentan hacer lo posible antes, conseguir la terminología... Pero, por ejemplo, desde hace años ya hablo de «la lucha por el Power Point», ¿no? Tú te vas al congreso un poco antes y buscas el Power Point que van a utilizar. Ahora todo eso es imposible. O te lo manda quien te contrata o tú, sigo con el ejemplo, no puedes ir a Buenos Aires a por el Power Point. O te lo han mandado antes o ya está. Sin embargo, yo ya tenía por costumbre «me voy al congreso una hora antes, me voy al técnico que mete todos los Power Point en el ordenador para proyectarlos», y yo de ahí me los llevaba. Eso ha desaparecido. Entonces, ¿cómo consigues la documentación antes? Yo he hecho congresos en remota muy difíciles, de cáncer, de tecnología, etc., y no me llegó la documentación. ¿Y cómo te enfrentas a una descripción de cirugía cardiovascular sin tener la documentación antes? Es muy complicado, son montones de desventajas que se van acumulando y que tenemos que empezar a tratar y a hablar de ellas, porque si alguien no lo hace, no se va a arreglar. Ahí, tanto el cliente como el organizador del congreso, te pueden ayudar en cierta medida, pero no del todo.

MDLC: La interpretación simultánea, la interpretación de conferencias, si se ha caracterizado por algo es la gran dependencia que tiene de los desarrollos tecnológicos, eso está claro. Desde el micrófono, hasta ver que la latencia sea la correcta para

Óscar JimÉnEz SERRANo

Hay primeros estudios que indican que se ha trasladado el grueso de la interpretación a la remota
CLINA

vol. 7-1, June 2021, 43-55

eISSN: 2444-1961

Ediciones Universidad de Salamanca - CC BY-NC-ND 
que pudiéramos trabajar correctamente, las cabinas, se ha desarrollado muchísimo la ISO... Y ahora, de repente, nos dicen que todo está en la red, que la red es la solución a todo, es el nuevo paradigma y que todo lo ha solucionado la red. Los intérpretes vamos a poder tener toda la información necesaria, nos vamos a poder conectar por súper autopistas de la información, estamos esperando que llegue el 5G, a lo mejor nos soluciona el $5 \mathrm{G}$ el problema que tenemos de conexión. Sabemos que no solo es un problema de conexión de 5G, sino el de los nodos que se sobrecargan. Pero bueno, lo que yo quería decir, lo que yo quería preguntarte. Con esta idea utópica, que se nos plantea ahora ya como realidad, el cambio de mentalidad para nosotros, para una generación que no hemos nacido dentro de la red como tú y yo, no se está dando, realmente es un choque cultural para nosotros. Pero, ¿cómo ves que se está dando este cambio de mentalidad debido a ese atropello que estamos sufriendo, debido a la crisis? Que parece que la crisis lo justifica absolutamente todo.

OJS: Pues, si me permites, me voy a extender un poquito más, porque es una pregunta interesantísima y tiene varios factores que señalar. En primer lugar, el tema de las conexiones. Está muy bien todo eso de las autopistas de la información, pero yo os estoy hablando desde el Albaicín en Granada, tengo 8 megas de velocidad. Entonces, gracias a Dios, estamos pudiendo hablar, pero no puedo tener más, porque aquí parece que jamás va a llegar la fibra. Y estamos en 2020, pero es patrimonio de la UNESCO, no se atreven a hacer agujeros en la calle y no se puede. ¿Yo qué voy a hacer? Yo vivo aquí, yo tengo que trabajar aquí. Entonces, se está hablando mucho ahora de los hubs. No sé si lo habéis leído en el artículo, que es una palabra evidentemente británica, en inglés, que se está utilizando para sitios donde se ubican los intérpretes, o bien alquilando tipo coworking, o bien se juntan varios y tienen un sitio, o bien alguien les alquila ese espacio en el que sí se garantizan esas condiciones, que hay alta velocidad de internet, una cabina aislada, etc. Eso puede ser parte del futuro y, de hecho, está pasando. Ya hay movimientos, empiezo a verlos, de creación de hubs. En Madrid hay varios, seguramente en más sitios y yo hago, incluso, una entrevista a miembros de un hub en el artículo. Eso, por un lado. Luego, yo hablo mucho del traductor como cyborg. Doug Robinson tiene un artículo sobre esto muy interesante. Hay que empezar a hablar ya del intérprete como cyborg, rodeado de tecnología. Por ejemplo, anoche, en el partido que os contaba que estaba interpretando me prestaban un iPad y en ese iPad yo tenía que encender y apagar el micrófono en el iPad, luego mi micrófono personal, distinto, tenía que apagarlo y encenderlo. Son tantas cosas que al final tienes apéndices electrónicos por todas partes. Pero lo más interesante es que hay algo en el dossier que se le ha escapado a mucha gente, que hay un artículo de Nakamura, del principal exponente de la interpretación automática en el mundo, que yo estaba muy interesado en que publicara algo ahí, porque se anunció que en Japón este verano (aunque al final no se han celebrado los Juegos) se iba a producir interpretación

Óscar JIMÉNEZ SERRANO

Hay primeros estudios que indican que se ha trasladado el grueso de la interpretación a la remota
CLINA

vol. 7-1, June 2021, 43-55

elSSN: 2444-1961

Ediciones Universidad de Salamanca - CC BY-NC-ND 
automática. Sí, interpretación automática en el sentido de que desaparecía nuestra profesión y yo estaba muy preocupado, quería saber qué opinaba y conseguí, después de muchísimos esfuerzos (el artículo estuvo a punto de no poder entrar), que me confirmara que efectivamente no es así. No se iba a dar una interpretación automática de conferencias, es decir, una rueda de prensa de los Juegos Olímpicos no se iba a hacer por parte de una máquina. Pero sí iban a tener ya dispositivos para que tú, por ejemplo, puedas coger un taxi en Tokio para ir a la sede de los Juegos Olímpicos, y pudieras hablar con el taxista y decirle dónde querías ir con una aplicación que interpretaba automáticamente. Yo creo que todo esto hay que tenerlo en cuenta, porque en el momento que eso llegue es el fin de nuestra profesión, si se produce ya a gran escala. $\mathrm{Y}$ ha pasado desapercibido, nos han dicho que de momento no, pero tengo montones de recortes de prensa diciendo que iba a pasar eso los Juegos Olímpicos. Me parece un tema interesantísimo y también multifacético.

MDLC: Pues acabamos con esa idea del cyborg de la interpretación, ya 4.0 dentro de esta industria 4.0 de la que se hablaba que iba a implantarse en el 2020 y estamos esperando todavía, pues parece que se está implantando a marchas forzadas. Te agradecemos muchísimo que hayas aceptado nuestra invitación. La verdad es que teníamos muchísimas ganas de poder hablar sobre remota, de poder plantear estos problemas que, además, no solamente son problemas técnicos, sino que son problemas que afectan al punto de vista ético, al punto de vista de cómo va a cambiar la profesión, de qué vamos a vivir, lo que ha dicho Juan. ¿Vamos a poder vivir de la interpretación? ¿Hoy en día todavía se puede vivir? ¿Cómo afecta a los costes, cómo está afectando también a las tarifas de interpretación? Todo esto tiene unas implicaciones muy profundas.

OJS: Sí, muy importante también esto. Por desgracia la eclosión tremenda a partir de marzo de la interpretación remota ha hecho que los clientes se den cuenta de que pueden conseguir una manera más barata de hacer las interpretaciones, porque no tienen que montar una cabina, alquilar un lugar donde realizar el congreso, etc. Y la ola se está llevando también nuestras tarifas. Está empezando a ser difícil respetar las tarifas que, afortunadamente, a diferencia de lo que ocurre con el mundo de la traducción, en el que hay gente cobrando 3 céntimos y gente cobrando veintitantos, han sido muy uniformes, por un corporativismo que ha funcionado muy bien, protegiendo esas condiciones de trabajo; y que yo creo que, en los 30 años que llevo en esto, se ha conseguido. Ha habido incluso reuniones cuando se ponía en peligro y se ha conseguido reaccionar, pero ahora está empezando a cambiar la cosa. De hecho, yo ya he pasado varios presupuestos con las tarifas habituales que me decían que cómo le iba a cobrar por una hora de Zoom esa barbaridad. Porque ven que ahora es otro tipo de trabajo y que por eso hay que cobrar menos, porque tú estás en tu casa y es mucho más fácil de hacer. Entonces hay que ver todavía cómo va a evolucionar esto. Hay clientes

Óscar JimÉnEz SERRANO

Hay primeros estudios que indican que se ha trasladado el grueso de la interpretación a la remota
CLINA

vol. 7-1, June 2021, 43-55

elSSN: 2444-1961

Ediciones Universidad de Salamanca - CC BY-NC-ND 
que se dan cuenta de la calidad de la interpretación que compran y son capaces de pagar esas tarifas, pero creo que va a segmentarse el mercado. Se va a producir un mercado gris en el que el que pasa por allí puede hacer una especie de apaño y cobrar muy poco, y luego habrá unos congresos más importantes, unas reuniones más importantes, en las que no te fías de contratar a alguien que pueda hacerlo así. Luego, por terminar en esa línea, también hay que tener en cuenta que toda la gente joven tiene que empezar a trabajar y, claro, cuando tú ves que pasa un año, dos años que has acabado la carrera y que no encuentras trabajo dices; «voy a intentar encontrarlo, aunque sea cobrando menos"; y ese es un tema en el que no quiero entrar, porque es muy muy complicado y hay mucho que hablar al respecto. Pero todo eso hay que tenerlo en cuenta. Entonces, vamos a intentar seguir defendiendo nuestras tarifas, que mucha gente ve o ha visto siempre como caras, son un servicio caro, pero que el que sabe lo que significa la interpretación, sobre todo simultánea, la suele valorar.

MDLC: Por último, ¿cómo quedó el Granada?

OJS: Pues el Granada ganó 2-1 afortunadamente y ayer, te cuento una anécdota personal muy emotiva, sabes que antes de ayer murió Diego Armando Maradona. Además de interpretar, parte del trabajo fue hacer de speaker en inglés en el partido y tuve el honor de anunciar en inglés el minuto de silencio por Diego Armando Maradona. Yo estoy muy emocionado porque, para mí, que soy muy futbolero y era muy fan, para mí ha sido el mejor jugador de todos los tiempos, muy interesante. Pero ganamos 2-1 y yo creo que pasaremos.

MDLC: Fenomenal. Eso me encanta. Muchísimas gracias.

OJS: Muchísimas gracias a todos.

\author{
Entrevista: «Don de Lenguas, Manuel de la Cruz, Martín Azcárate, Rosa Weber, Miguel \\ Prieto, Juan de la Puente » \\ Transcripción: Beatriz Guerrero García \\ Enlace: https://www.ivoox.com/entrevista-a-oscar-jimenez-serrano-audios-mp3_rf_61289500_1.htm/ \\ Duración: 34:55:00
}

Óscar JIMÉNEZ SERRANO

Hay primeros estudios que indican que se ha trasladado el grueso de la interpretación a la remota
CLINA

vol. 7-1, June 2021, 43-55

elSSN: 2444-1961

Ediciones Universidad de Salamanca - CC BY-NC-ND 


\title{
NOTA BIOGRÁFICA
}
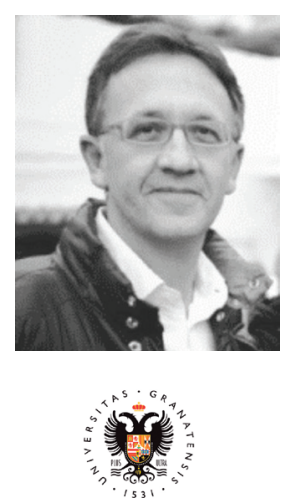

UNIVERSIDAD

DE GRANADA

Óscar Jiménez Serrano es traductor e intérprete profesional con más de 30 años de experiencia. Es profesor titular del Departamento de Traducción e Interpretación de la Universidad de Granada. En los últimos años su actividad se ha centrado en la relación que existe entre la Interpretación y las Nuevas tecnologías. Ha impartido talleres y seminarios en instituciones nacionales e internacionales.

\author{
Óscar Jiménez Serrano: \\ https://orcid.org/0000-0002-5761-114X
}

\section{BIBLIOGRAFÍA}

Jiménez Serrano, Óscar. 2020. «Foto fija de la interpretación simultánea remota al inicio del 2020». Tradumática. DOI: 10.5565/rev/tradumatica.239

Jiménez Serrano, Óscar. 2019. «Tecnologías de la interpretación». Tradumàtica. DOI: 10.5565/ rev/tradumatica.240 